\title{
Paradis pour une reine. Le monastère de Qoma
} Fasilädäs, Éthiopie

Paris, Publications de la Sorbonne, 2012, 479 p., bibl., index, ill.

\section{Serge-Pierre Dewel}

\section{(2) OpenEdition}

\section{Journals}

\section{Édition électronique}

URL : http://journals.openedition.org/etudesafricaines/18059

DOI : 10.4000/etudesafricaines. 18059

ISSN : $1777-5353$

Éditeur

Éditions de l'EHESS

Édition imprimée

Date de publication : 1 avril 2015

ISSN : 0008-0055

\section{Référence électronique}

Serge-Pierre Dewel, « Paradis pour une reine. Le monastère de Qoma Fasilädäs, Éthiopie », Cahiers

d'études africaines [En ligne], 217 | 2015, mis en ligne le 31 mars 2017, consulté le 24 septembre 2020.

URL : http://journals.openedition.org/etudesafricaines/18059; DOI : https://doi.org/10.4000/

etudesafricaines. 18059

Ce document a été généré automatiquement le 24 septembre 2020.

(c) Cahiers d'Études africaines 


\title{
Paradis pour une reine. Le monastère de Qoma Fasilädäs, Éthiopie
}

Paris, Publications de la Sorbonne, 2012, 479 p., bibl., index, ill.

\author{
Serge-Pierre Dewel
}

\section{WION, Anaïs. - Paradis pour une reine. Le monastère de Qoma Fasilädäs, Éthiopie, $x{ }^{e}{ }^{e}$ siècle. Paris, Publications de la Sorbonne, 2012, 479 p., bibl., index, ill.}

1 L'ouvrage d'Anaïs Wion est le produit d'une recherche de grand intérêt pour l'histoire de l'Éthiopie. Se fondant sur une histoire orale pluriséculaire, sur les archives paroissiales et sur l'étude d'un patrimoine local, l'auteure a ressuscité un des chapitres oubliés par l'historiographie officielle. Pour en ressusciter un des chapitres, l'auteure se fonde sur une tradition (et histoire) orales pluriséculaires, sur les archives paroissiales et sur l'observation patrimoniale. L'originalité de ce travail, avant tout, repose précisément sur l'emploi de la première de ces sources. En effet, si la tradition orale fut l'objet d'attentions depuis Marcel Griaule, il demeure exceptionnel que les sources orales, afä tarik, soient considérées comme sources historiques dans les recherches consacrées aux hautes terres septentrionales d'Éthiopie. Sans doute un héritage laissé aux études éthiopiennes par ses pionniers qui furent avant tout des orientalistes.

2 Les trois catégories de sources sont minutieusement analysées afin de restituer le pan d'histoire qui suit. D'abord, les vestiges sont replacés dans une fourchette chronologique stable, essentiellement par la méthode comparative. Il en ressort ainsi que le merveilleux ensemble de peintures murales compte parmi les seuls quatre exemples du «premier style gondarien» (XvII ${ }^{e}$ siècle). Les sources orales, minutieusement transcrites en annexes, sont analysées et confrontées, non sans que la méthodologie de collecte soit précisément exposée. Cette approche méthodologique 
permet au lecteur de se familiariser avec l'environnement social et de mieux appréhender la valeur des informations, tant sur les événements que sur les institutions, foncières par exemple. Enfin, les sources écrites, en langue guèze et en arabe aussi, furent finalement accessibles : la règle du monastère (s'erit), les textes des donations foncières (waqf) rédigés en arabe par le patriarche copte d'Alexandrie ${ }^{22}$, les actes d'octroi royaux de terres au bénéfice du monastère (le gult) que l'on qualifierait improprement d'apanages ou de fiefs, et l'acte de fondation. Ces textes existent en plusieurs versions à Qoma Fasilädäs.

3 Avec ces sources à sa disposition, Anaïs Wion relate la fondation du monastère et son imbrication dans le chaos politique et religieux de la première moitié du XVII siècle ; ce corpus lui permet aussi de suivre les évolutions foncières du domaine. Tout commence en 1624, lorsque le souverain SusEnyos convertit son pays au catholicisme, se plaçant ainsi en position minoritaire. Au-delà du clergé et du peuple, Wäld S'äala, son épouse, ne compte pas plus parmi ses nouveaux coreligionnaires, aussi finit-il par abdiquer en faveur de son fils Fasilädäs en 1634, du moins selon l'historiographie officielle. Ce dernier est connu pour être le restaurateur de l'orthodoxie chrétienne éthiopienne, le fondateur de la capitale impériale à Gondar mais aussi pour ses violentes querelles avec le clergé. C'est dire si la fondation du monastère de Qoma Fasilädäs se fit durant une période-clé de l'histoire politique de l'Éthiopie. Une singularité méritant d'être soulignée est qu'à Qoma Fasilädäs, on considérait le jeune frère de Fasilädäs comme le dauphin légitime.

4 L'histoire de la fondation du monastère est aussi l'histoire-feuilleton de la famille royale : le roi SusEnyos, la reine Wäld S'äala et leurs fils Gälawdewos et Fasilädäs. S'étant querellée avec son époux, la reine cherche un territoire où fonder une église, un fief où se retirer mais aussi destiné à perpétuer sa mémoire familiale. Elle trouve ce domaine, suivant en cela des signes auguraux que relate la tradition, dans l'extrême sud du Bägemder, à la limite du Gog am et non loin duS äwa, proche de gorges dans lesquelles coule la rivière $\mathrm{Abay}^{23}$. La fondation, qui se place avant $1640^{24}$, constitue un temps zéro à partir duquel les sources écrites et orales de Qoma Fasilädäs permettent de reconstituer l'histoire que l'historiographie officielle a oubliée. C'est la généalogie de la reine que la Chronique du règne de son mari mentionne à peine, la stratégie matrimoniale de SusEnyos qui se reconstitue, le fratricide commis par Fasilädäs sur son Gälawdewos considéré à Qoma comme le souverain légitime qui apparaît au grand jour. Le souvenir de la reine-fondatrice a continué d'y être célébré jusqu'à l'époque actuelle ; ainsi, le $1^{\text {er }}$ du mois de megabit ${ }^{25}$, a lieu le täzkar, selon la tradition éthiopienne. Fête capitale de l'Église, il s'agit de la commémoration de la mort de la reine, le jour anniversaire de son décès.

5 Cependant, le domaine du monastère n'a pu exister que par la donation d'un roi dont le nom est difficilement prononcé par le clergé orthodoxe ${ }^{26}$. La situation est d'autant plus embarrassante que c'est le souverain restaurateur, fratricide et rejeté par sa mère qui en est la fondatrice, qui donne son nom au domaine. Comment les archives et la tradition de Qoma Fasilädäs se sont accommodées de cette origine gênante est une étape importante du travail de construction auquel se livre l'auteure. Le nom de l'un a soigneusement été effacé des manuscrits, alors que celui de l'autre, en dépit du fratricide et du rejet maternel, est omniprésent par la toponymie, cependant seulement salué par une apparition lapidaire dans les Chroniques brèves tardives de l'historiographie officielle. Fasilädäs est un sujet d'énigme. D'abord consacré à 
Gälawdewos, Qoma porte finalement le nom de l'usurpateur. Comment le frère cadet avait-il pu à ce point monter en puissance pour que l'indicible soit commis ? Quoi qu'il en soit, et cela n'a rien d'étonnant, le meurtre du cadet par l'aîné est tu dans l'histoire officielle.

Par ailleurs, les sources documentent aussi l'organisation paroissiale, peu connue pour la période moderne. Celle de Qoma est en effet considérée comme demeurant inchangée depuis sa fondation au XVII siècle. De l'avis des témoins, les seules modifications statutaires ou structurelles le furent sous le régime du Därg ${ }^{27}$. Le territoire paroissial est organisé autour du monastère avec des églises dépendantes. L'ensemble jouit d'une forme d'extraterritorialitée ${ }^{28}$, sorte de petite "principauté paroissiale » dont les limites territoriales sont l'objet d'attention et dont le pouvoir est exercé avec collégialité "démocratique ». Le détail de la complexité des charges, de leur renouvellement et des conditions d'élection fait l'objet d'un chapitre important, lui aussi.

7 Bien que principalement concentrée sur la période qui suit l'expulsion des catholiques et les débuts des grandes querelles religieuses, cette étude s'attache peu à la question des divisions que l'Église éthiopienne commence à connaître. De l'aveu de l'auteure, il resterait beaucoup de travail à réaliser pour constituer un apport à la connaissance des identités religieuses des $\mathrm{XVII}^{\mathrm{e}}$ et $\mathrm{XVIII}{ }^{\mathrm{e}}$ siècles. Dans la forme, nous pouvons regretter la dispersion de la bibliographie en plusieurs parties, tout comme la remise à zéro de la numérotation des notes à chaque chapitre qui ne facilite pas la lecture.

L'ouvrage, publication de la thèse de doctorat de l'auteure, constitue un apport capital par sa méthodologie originale et sa qualité. Ainsi, sont mises en lumière les difficultés qui entravent la succession royale, les troubles qui accompagnent ces périodes et les efforts que doivent consentir les nouveaux souverains pour assoir leur autorité. Audelà de la description de ce domaine, paradis pour une reine s'entourant de paix, d'artistes et d'intellectuels, cette étude détaille de manière approfondie l'espace qui s'est creusé entre l'histoire telle qu'elle puisse être reconstituée sur base de sources nouvelles (celles de Qoma Fasilädäs) et celle établie par l'historiographie officielle. Avec une conception étendue des sources historiques (patrimoniales, orales et écrites), l'auteure se livre à ce travail d'enquête, cependant que le domaine de Qoma n'offrait aucune tradition historiographique.

\section{NOTES}

22. Jusqu'en 1959, date de son accès à l'autocéphalie, l'Église " orthodoxe » d'Éthiopie était placée sous la tutelle de l'Église copte d'Alexandrie qui envoyait un métropolite en résidence en Éthiopie.

23. Le Nil Bleu.

24. Selon l'auteure, l'église est achevée vers 1640-1641.

25. Le 10 mars. 
26. En raison de la conversion de Sus?nyos à l'Église catholique.

27. 1974-1991.

28. Je n'oserais dire à l'image du Vatican dans l'Italie, mutatis mutandis. 